\title{
Generation and ring opening of aziridine $N$-carbonyl radicals
}

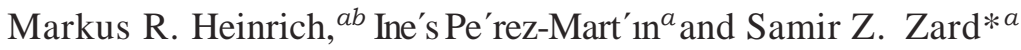 \\ Received (in Cambridge, UK) 13th September 2005, Accepted 6th October 2005 \\ First published as an Advance Article on the web3rd November 2005 \\ DOI: $10.1039 / \mathrm{b} 512956 \mathrm{~g}$
}

Aziridine $N$-carbonyl radicals, generated by irradiating the corresponding $S$-oxalyl xanthates, undergo ring opening to give 2-isocyanato radicals, which can be trapped by an external olefin.

We recently found that cyclopropylacyl radicals add to external, unactivated olefins in preference to extrusion of carbon monoxide. ${ }^{1}$ In an extension to this work aimed at generating radical 1 (Scheme 1) and using it to produce unusual aziridinyl amino acid derivatives such as 2 and 3, we isolated hemi-oxalamide chloride 4a (R $5{ }^{i} \mathrm{Pr}$ ) and the corresponding xanthate $5 \mathrm{a}$ as a side product in one reaction and were surprised to find this compound sufficiently stable to be purified by chromatography. This was in contrast to the difficulties recently reported for the synthesis of xanthates from carbamoyl chlorides. ${ }^{2}$ We therefore decided to exploit this
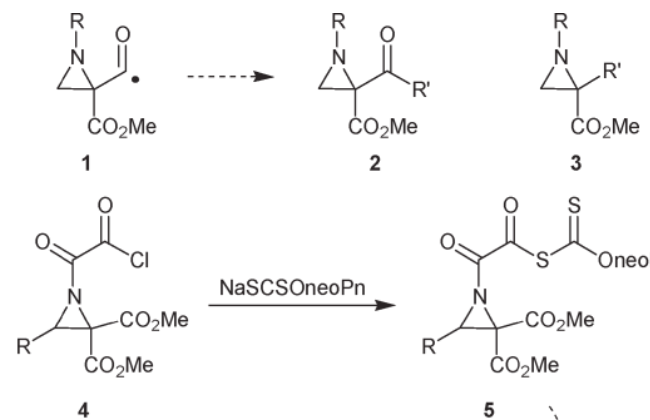

2

3

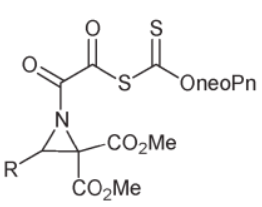<smiles>[R]C(N=C=O)C(C(C)=O)C(C)=O</smiles>

5
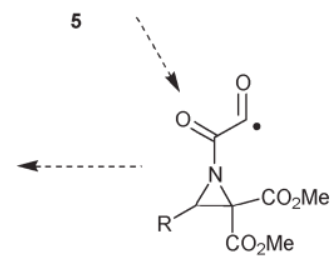

8 6

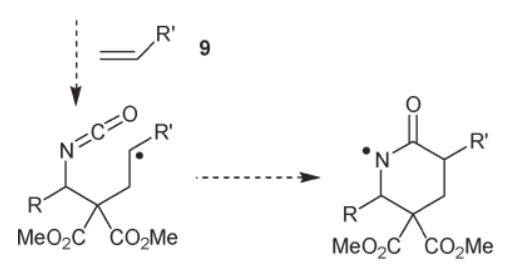

10
11

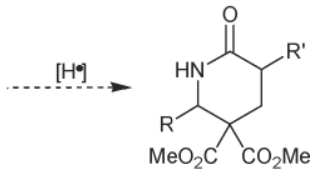

12
Scheme 1 Possible evolution of an aziridine $N$-carbonyl radical.

${ }^{a}$ Organische Chemie 1, Technische Universita 4, D-85747 Garching, Germany.E-mail: Markus.Heinrich@ch.tum.de

${ }^{b}$ Laboratoire de Synthe 'se Organique associe' au C.N.R.S., Ecole

Polytechnique, F-91128 Palaiseau, France.

E-mail: zard@poly.polytechnique.fr; Fax: +33 169333851;

Tel: +33169334872 serendipitous finding to study the behaviour of aziridinyl $\mathrm{N}$ carbonyls, a family of reactive intermediates that has not been studied as far as we are aware. ${ }^{3}$

On the basis of previous related observations, ${ }^{4}$ it seemed reasonable to assume that carbonyl radicals 6 , produced upon irradiation of xanthates $5,{ }^{5}$ would rapidly lose carbon monoxide to give carbamoyl radicals 7 . Ring opening, encouraged by the presence of the two stabilising ester groups, would lead to an isocyanate radical 8 , which could perhaps be captured by addition to an external olefin 9. We believed that the adduct radical 10 would then add to the isocyanate group to furnish cyclic amidyl radical 11, by analogy with the observations of Walton and Minin, ${ }^{6}$ and the latter could possibly abstract a hydrogen from the solvent to give finally lactam 12 .

The preparation of the requisite xanthates 5 involves first the construction of the aziridine ring by reaction of $\mathrm{N}, \mathrm{O}$ bis(trimethylsilyl) hydroxylamine with malonylidene deriva- tives according to the recent procedure described by Cardillo et al. ${ }^{7}$ The resulting aziridine is then treated with a three-fold excess of oxalyl chloride and the crude acid chloride 4 , obtained by evaporation of the solvent and unreacted oxalyl chloride, is dissolved in ethyl acetate and cooled to $275 \mathrm{uC}$, whereupon sodium $O$-neopentyl xanthate is added and the reaction allowed to proceed at the same temperature for $30 \mathrm{~min}$. The yellow xanthate can be obtained pure by chromatography but this is not usually necessary.

When xanthate $5 \mathrm{a}$ and trimethyl vinylsilane were dissolved in 1,2-dichloroethane and irradiated with a $250 \mathrm{~W}$ tungsten-halogen lamp, a reasonably clean reaction ensued but we were surprised to find that the main product was in fact isocyanate 13a, as indicated by the strong band at $2269 \mathrm{~cm}^{21}$ in the IR spectrum (Scheme 2). \{ It was isolated in $24 \%$ yield and consisted of a 1.3:1 mixture of diastereoisomers. Clearly, compound 13a results from the<smiles>CCOC(=O)SC(=S)C(=O)N1C(C(C)C)C1(C(C)=O)C(C)=O</smiles>

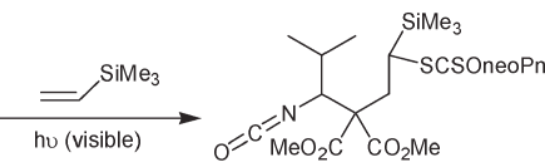

$5 a$

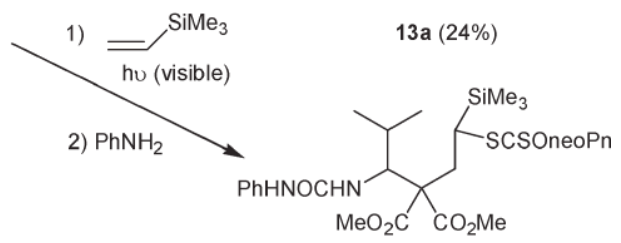

$14 \mathrm{a}(20 \%)$ 
premature capture of intermediate radical 10a $\left(10, \mathrm{R} 5{ }^{i} \mathrm{Pr}\right)$ by the starting xanthate 5a.

As far as we are aware, this is the first observation of a ring opening of an aziridine leading to an isocyanate. The absence of ring closure of the intermediate radical 10a to the isocyanate group is puzzling and contrasts with earlier findings of Walton and Minin, ${ }^{6}$ and cyclisations involving ketenes. ${ }^{8}$ The possibility of a reversible addition seems unlikely since there is no obvious driving force to cause the amidyl radical to fragment into a strained isocyanate and an unstabilised secondary radical. ${ }^{9}$ The radical addition to the isocyanate must therefore be a relatively slow process and does not occur in the present case, despite the presence of the geminal ester groups exerting, in principle, a favourable Thorpe-Ingold type effect.

The unexpected formation of a reactive isocyanate opens up the possibility of accomplishing a multicomponent sequence leading to fairly complex structures, for example by adding an amine or an alcohol at the end of the irradiation period. The first attempt using aniline gave a disappointing yield of the corresponding urea $14 \mathrm{a}$ (Scheme 2), but the more reactive and more useful ethyl glycinate and aminoacetonitrile gave generally acceptable yields of the desired product (Table 1).

All three components can be varied as indicated by the examples collected in Table 1. The main limitations derive from a lack of flexibility and difficulties associated with the synthesis of the starting aziridines 5 . The overall yields are modest, but it must be remembered that the product arises following a complex sequence involving a large number of individual steps and highly reactive intermediates. It is also necessary to capture the isocyanate selectively without partially cleaving the xanthate group or the ester groups. Xanthates are known to be somewhat more labile than esters with respect to aminolysis. ${ }^{10}$ Capture by an alcohol to

Table 1 Synthesis of ureas by a radical-ionic sequence

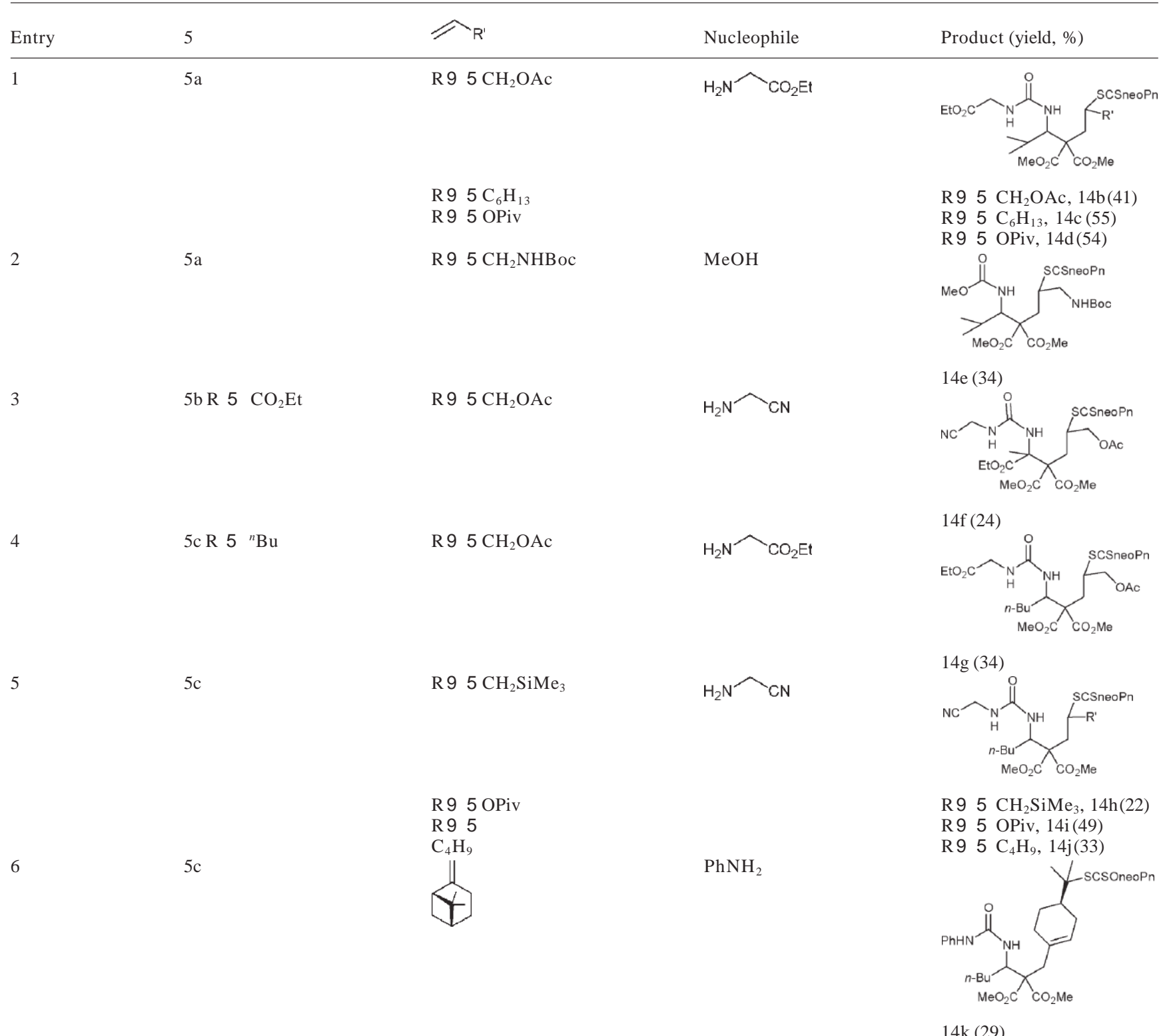


give a urethane is illustrated by the transformation in entry 2 and an addition-fragmentation sequence is exemplified by the reaction with $b$-pinene (entry 6).

In summary, this preliminary study has highlighted the ready generation of isocyanate from aziridine derivatives. The scope of this reaction, especially as concerns the nature of the substituents on the aziridine ring and their influence on the ring opening step, remains to be examined in more detail; nevertheless, the sequence as it now stands allows an expedient access to otherwise not readily available derivatives.

I. P.-M. thanks the M. E. C. y D. (Spain) and M. R. H., the Alfred Kastler Foundation, for a postdoctoral fellowship.

\section{Notes and references}

\{ General procedure for the synthesis of isocyanates and further derivatives: A solution of xanthate $5(1 \mathrm{mmol})$ and olefin $(18 \mathrm{mmol})$ in $\mathrm{CH}_{2} \mathrm{Cl}_{2}(0.5 \mathrm{~mL})$ was irradiated under argon with a $250 \mathrm{~W}$-lamp until all starting material was consumed (4-8 h). The crude product was concentrated under reduced pressure and added to a solution of the nucleophile $(1 \mathrm{mmol})$ and ${ }^{i} \mathrm{Pr}_{2} \mathrm{NEt}$ $(2 \mathrm{mmol})$ at $0 \mathrm{uC}$. Total consumption of the isocyanate was monitored by IR spectroscopy. The solution was concentrated under reduced pressure and the residue was submitted to column chromatography. Compound $14 \mathrm{i}$, as a mixture of diastereomers $D_{1} / D_{2}(1: 1)$ : IR $\left(\mathrm{CCl}_{4}, \mathrm{~cm}^{21}\right) 3401,2958$, $1743,1698,1539,1275,1231 .{ }^{1} \mathrm{H}$ NMR $\left(\mathrm{CDCl}_{3}, 400 \mathrm{MHz}\right) 0.87(3 \mathrm{H}, \mathrm{dd}$, $J 56.4,6.4 \mathrm{~Hz}), 0.92(3 \mathrm{H}, \mathrm{dd}, J 57.2,7.2 \mathrm{~Hz}), 1.03(9 \mathrm{H}, \mathrm{s}), 1.17(9 \mathrm{H}, \mathrm{s})$, $1.19-1.65\left(12 \mathrm{H}, \mathrm{m}, \mathrm{D}_{1}+\mathrm{D}_{2}\right), 2.62(1 \mathrm{H}, \mathrm{dd}, J 56.4,15.2 \mathrm{~Hz}), 2.73(1 \mathrm{H}, \mathrm{dd}$, $J 55.2,15.0 \mathrm{~Hz}), 2.80(2 \mathrm{H}, \mathrm{m}), 3.75(3 \mathrm{H}, \mathrm{s}), 3.76(3 \mathrm{H}, \mathrm{s}), 3.78(6 \mathrm{H}, \mathrm{s}), 3.82$ $(2 \mathrm{H}, \mathrm{s}), 3.90(2 \mathrm{H}, \mathrm{s}), 4.24\left(2 \mathrm{H}, \mathrm{dd}, J 5 \quad 4.4,6.0 \mathrm{~Hz}, \mathrm{D}_{1}+\mathrm{D}_{2}\right), 4.27(4 \mathrm{H}, \mathrm{s})$, $5.70\left(2 \mathrm{H}\right.$, br s, $\left.\mathrm{D}_{1}+\mathrm{D}_{2}\right), 5.90\left(2 \mathrm{H}, \mathrm{m}, \mathrm{D}_{1}+\mathrm{D}_{2}\right), 6.74(1 \mathrm{H}, \mathrm{dd}, J 56.7$, $6.7 \mathrm{~Hz}), 6.80(1 \mathrm{H}, \mathrm{dd}, J 5 \quad 5.2,8.4 \mathrm{~Hz}) .{ }^{13} \mathrm{C} \mathrm{NMR}\left(\mathrm{CDCl}_{3}, 100 \mathrm{MHz}\right) 13.8$
$\left(\mathrm{CH}_{3}\right), 13.9\left(\mathrm{CH}_{3}\right), 22.1\left(\mathrm{CH}_{2}\right), 22.4\left(\mathrm{CH}_{2}\right), 26.5\left(36 \mathrm{CH}_{3}\right), 26.8(36$ $\left.\mathrm{CH}_{3}\right), 27.6\left(\mathrm{CH}_{2}\right), 28.4\left(\mathrm{CH}_{2}\right), 28.6\left(\mathrm{CH}_{2}\right), 28.8\left(\mathrm{CH}_{2}\right), 31.5\left(26 \mathrm{CH}_{2}\right.$, $\left.\mathrm{D}_{1}+\mathrm{D}_{2}\right), 31.8\left(26 \mathrm{C}_{\mathrm{q}}, \mathrm{D}_{1}+\mathrm{D}_{2}\right), 38.1\left(\mathrm{CH}_{2}\right), 38.3\left(\mathrm{CH}_{2}\right), 38.8\left(26 \mathrm{C}_{\mathrm{q}}\right)$, $52.7\left(\mathrm{CH}_{3}\right), 52.9\left(\mathrm{CH}_{3}\right), 53.3\left(\mathrm{CH}_{3}\right), 54.1\left(\mathrm{CH}_{3}\right), 55.3(\mathrm{CH}), 55.4(\mathrm{CH}), 61.3$ $\left(\mathrm{C}_{\mathrm{q}}\right), 61.4\left(\mathrm{C}_{\mathrm{q}}\right), 78.4(\mathrm{CH}), 78.6(\mathrm{CH}), 83.6\left(26 \mathrm{CH}_{2}, \mathrm{D}_{1}+\mathrm{D}_{2}\right), 158.1(26$ $\left.\mathrm{C}_{\mathrm{q}}, \mathrm{D}_{1}+\mathrm{D}_{2}\right), 164.3\left(\mathrm{C}_{\mathrm{q}}\right), 165.7\left(\mathrm{C}_{\mathrm{q}}\right), 169.8\left(\mathrm{C}_{\mathrm{q}}\right) 170.0\left(\mathrm{C}_{\mathrm{q}}\right), 170.1\left(\mathrm{C}_{\mathrm{q}}\right), 176.5$ $\left(\mathrm{C}_{\mathrm{q}}\right), 210.2\left(\mathrm{C}_{\mathrm{q}}\right), 210.4\left(\mathrm{C}_{\mathrm{q}}\right)$. HRMS calcd for $\mathrm{C}_{26} \mathrm{H}_{43} \mathrm{O}_{8} \mathrm{~N}_{3} \mathrm{~S}_{2} ; 589.24915$, found 589.24906 .

1 M. R. Heinrich and S. Z. Zard, Org. Lett., 2004, 6, 4969.

2 R. S. Grainger and P. Innocenti, Angew. Chem., Int. Ed., 2004, 43, 3445.

3 The closest process we have found is the fragmentation of $N$-acyl aziridines upon electron transfer from a naphthalenide radical anion, studied by the group of H. Stamm: T. Mall and H. Stamm, J. Chem. Soc., Perkin Trans. 2, 1997, 2135; J. Werry, P.-Y. Lin, P. Assithianakis and H. Stamm, J. Chem. Soc., Perkin Trans. 1, 1995, 3103, and earlier references cited therein.

4 For a review on acyl radicals, see: I. Ryu, N. Sonoda and D. P. Curran, Chem. Rev., 1996, 96, 177.

5 For general reviews see: S. Z. Zard, Angew. Chem., Int. Ed. Engl., 1997, 36, 672; S. Z. Zard, "Xanthates and Related Derivatives as Radical Precursors" in Radicals in Organic Synthesis, ed. P. Renaud and M. P. Sibi, Wiley-VCH, Weinheim, 2001, vol. 1, p. 90.

6 J. C. Walton and P. L. Minin, Org. Biomol. Chem., 2004, 2, 2471; J. C. Walton and P. L. Minin, J. Org. Chem., 2003, 68, 2960. See also: P. Kaushal and B. P. Roberts, J. Chem. Soc., Perkin Trans. 2, 1989, 1559 .

7 G. Cardillo, L. Gentilucci, M. Gianotti, R. Perciaccante and A. Tolomelli, J. Org. Chem., 2001, 66, 8657.

8 N. Herbert and G. Pattenden, Synlett, 1997, 69; B. De Boeck and G. Pattenden, Tetrahedron Lett., 1998, 39, 6975; B. De Boeck, N. Herbert and G. Pattenden, Tetrahedron Lett., 1998, 39, 6971.

9 E. Bacque', M. El Qacemi and S. Z. Zard, Org. Lett., 2005, 7, 3817.

10 K. Mori and Y. Nakamura, J. Org. Chem., 1969, 34, 4170. 